\title{
Humoral immune response in hens naturally infected with Salmonella Enteritidis against outer membrane proteins and other surface structural antigens
}

\author{
Javier OCHOA-REPÁRAZ ${ }^{\mathrm{a}}$, Begoña SESMA ${ }^{\mathrm{b}}$, Miguel ÁlVAREZ ${ }^{\mathrm{c}}$, \\ M. Jesús RENEDO ${ }^{\mathrm{d}}$, Juan M. IRACHE ${ }^{\mathrm{d}}$, Carlos GAMAZO ${ }^{\mathrm{a} *}$ \\ a Departamento de Microbiología, Universidad de Navarra, 31008 Pamplona, Spain \\ b Instituto Salud Pública de Navarra, 31004 Pamplona, Spain \\ ${ }^{c}$ Lab. Municipal de Pamplona, 31004 Pamplona, Spain \\ ${ }^{\mathrm{d}}$ Centro Galénico, Universidad de Navarra, 31008 Pamplona, Spain
}

(Received 8 September 2003; accepted 19 December 2003)

\begin{abstract}
A simple procedure for obtaining surface exposed antigens of Salmonella Enteritidis is described. A heat treatment of whole bacteria in saline solution induced the release of small membrane vesicles containing outer membrane components as well as surface appendage components, such as fimbriae and flagellin. The characterization of the structural components of this extract, called HE, was established by SDS-PAGE and immunoblotting using polyclonal and monoclonal specific antibodies. Five major groups of proteins were identified: flagellin, porins, OmpA, SEF21 and SEF14 fimbriae. The immunogenicity of these proteins was studied by immunoblotting with serum samples from naturally infected hens. Flagellin, porins, OmpA, SEF14 and SEF21 fimbriae were immunogenic in the $S$. Enteritidis infected hens (frequency of reactants: 47.3, 97.3, 64.7, 50.0 and 60.8\%, respectively); porins also reacted with sera from non infected hens (66.7\%). The immunogenicity of these antigens in infected birds provide promise that they may serve as components of an effective subcellular vaccine for poultry salmonellosis.
\end{abstract}

salmonellosis / immunoblotting / immunogenicity / surface antigens / hens

\section{INTRODUCTION}

Salmonella enterica serovar Enteritidis (Salmonella Enteritidis, SE) is a major cause of human food-borne illness and is the most frequent serovar detected in outbreaks of human salmonellosis [18]. Poultry products are known to be a significant reservoir for Salmonella and the most important source of SE infection in humans $[7,14,19,22]$.
Salmonella possess different surface structures that can induce protective immune responses in experimentally infected chickens $[16,30]$. Immunoblotting has been used previously to recognize antigenic polypeptides of SE in experimentally infected chickens [1]. Other workers have also used experimentally infected birds, by ELISA and other serological techniques, to determine the antigenicity of lipopolysaccharide (LPS), flagella and fimbriae [12, 23, 25, 28],

\footnotetext{
* Corresponding author: cgamazo@unav.es
} 
or whole cells [6]. However, to our knowledge, there is not any report in the literature showing the reactivity by immunoblotting of the SE antigens during the course of a natural infection in hens.

For purposes of vaccine development, the present study was accomplished to determine the main immunogenic outer components of SE in the course of a natural infection in hens. For this, a simple procedure for obtaining superficial antigens of $\mathrm{SE}$ is also described.

\section{MATERIALS AND METHODS}

\subsection{Serum samples}

A total of 104 serum samples from laying hens (7-11 months old) were studied. Serum samples in group $1(n=74)$ were obtained from $S$. Enteritidis naturally infected hens, from different flocks (as confirmed by rectal swab culture) and serum samples in group $2(n=30)$ were taken from salmonellae free hens (obtained from CESAC, Reus, Girona, Spain). Positive and negative control serum sample pools were prepared by pooling ten individual sera from infected hens and ten individual sera from salmonellae free hens, respectively. These controls were employed to validate the immunoblotting procedure used in this study.

\subsection{Bacterial strains and growth conditions}

The antigenic extract was obtained from the clinically isolated $S$. Enteritidis strain 3934 (Universitary Hospital of Navarra, Spain), that was grown in trypticase-soy broth (Biomérieux, Marcy-l'Étoile, France) in a rotary shaker at $37^{\circ} \mathrm{C}$ for $24 \mathrm{~h}$.

\subsection{Antigenic extract of $S$. Enteritidis}

A hot saline extract of $S$. Enteritidis (HE) was obtained following a procedure previ- ously used for the extraction of some $\mathrm{Bru}$ cella antigens [10]. Briefly, live cells were suspended in physiological saline (10 g of packed cells per $100 \mathrm{~mL}$ ) and heated in flowing steam for $15 \mathrm{~min}$. After centrifugation at $12000 \times g$ for $15 \mathrm{~min}$, the supernatant was dialyzed for two days at $4{ }^{\circ} \mathrm{C}$ against several changes of deionized water. The dialyzed material was centrifuged for $5 \mathrm{~h}$ at $100000 \times g$, and the pellet (HE extract) was resuspended in deionized water, lyophilized and stored at room temperature.

Outer membrane proteins (OMPs) from $S$. Enteritidis were prepared by sequential detergent extraction of cell envelopes [8]. Briefly, after the disruption of cells by high pressure in a French Press (Aminco-SLM Instuments Inc, Urbana, Illinois, USA), the inner membranes of the bacteria were solubilized after treatment with $1 \%$ Sarkosyl (N-Lauryl sarcosine, Sigma Chemical Co., St. Louis, USA) and centrifuging $(20000 \times$ $g$; $30 \mathrm{~min}$ ). The sediment was suspended in $0.5 \mathrm{M}$ Tris- $\mathrm{HCl}$ (pH 6.8) with $10 \%$ SDS (Lauryl sulfate, Sigma) and centrifuged $(20000 \times g ; 30 \mathrm{~min})$. The OMPs of $S$. Enteritidis were present in the final supernatant.

\subsection{Electron microscopy}

HE was resuspended in deionized water and stained with 4\% Uranyl acetate (Agar scientific) for $15 \mathrm{~min}$ and with lead citrate (Agar scientific) for $15 \mathrm{~min}$ and then was examined with a Hitachi 1100 transmission electron microscope (Hitachi Scientific Instruments, California, USA) operating at $100 \mathrm{kV}$.

\subsection{Chemical analysis}

Total protein content was determined colorimetrically [17], with bovine serum albumin as the standard. The LPS content of HE was estimated by colorimetric determination of 2-keto-3-deoxyoctonate corrected for 2-deoxyaldoses, performed by the method of Warren [32] as modified by Osborn [21]. 


\subsection{SDS-PAGE and immunoblotting procedure}

SDS-PAGE was performed in $15 \%$ acrylamide slabs by the method of Laemmli [15]. The gels were stained by the alkaline silver-glutaraldehyde method for proteins. The apparent molecular masses of the proteins present in the antigenic extracts were determined by comparing their electrophoretic mobility with that of the following molecular mass markers (Rainbow colored protein molecular weight marker, Amersham pharmacia biotech, Freiburg, Germany): myosin (220 kDa); phosphorylase b (97 kDa); bovine serum albumin (66 kDa); ovalbumin (45 kDa); carbonic anhydrase (30 kDa); trypsin inhibitor (20.1 kDa); lysozyme (14.3 kDa).

Immunoblotting was carried out as described by Towbin [31] with the following modifications: after SDS-PAGE, the gel was transferred in a transfer buffer (0.2 M glycine; 24 mM Tris; $10 \%$ methanol [pH 8.3]) to PVDF (polyvinylidene fluoride papers, pore size $0.45 \mu \mathrm{m}$, Schleicher and Schuell, Dassel, Germany) using a semidry electroblotter (Bio-rad Laboratories, Richmond, USA) (200 mA; $5 \mathrm{~V} ; 30 \mathrm{~min})$. The blots were placed in blocking buffer $(3 \%$ skimmed milk and $0.15 \%$ Tween-20 in $10 \mathrm{mM}$ phosphate-buffered saline [pH 7.4]) overnight at room temperature, and then they were incubated for $4 \mathrm{~h}$ at room temperature with hen serum sample diluted 1:100 in blocking buffer without skimmed milk. After four washes in blocking buffer without skimmed milk, the blots were incubated for one hour at room temperature with the immunoconjugate: peroxidase-conjugated rabbit anti-chicken IgG (Nordic Labs, Tilburg, The Netherlands), diluted 1:1000 in the same buffer. The blots were washed four times more, and were developed by incubation in a solution containing $\mathrm{H}_{2} \mathrm{O}_{2}$ and 4-chloro, 1-naphtol for $20 \mathrm{~min}$ in the dark.

The frequency of the reactants to the main structural components of HE extract was determined by computing the number of sera of natural infected hens that reacted against these components. Positive and negative control serum pools were used in all the experiments as an internal reference to validate the comparison of the experiments.

\subsection{Identification of the major components of $\mathrm{HE}$}

The presence of flagellin (FliC) and SEF14 were confirmed with specific monoclonal antibodies (kindly provided by Veterinary Laboratories Agency, Surrey, UK). SEF14 and SEF21 bands were recognized by comparison with the corresponding purified proteins obtained after a purification process based on a selective precipitation with $\left(\mathrm{NH}_{4}\right)_{2} \mathrm{SO}_{4}$ (50\% saturation); the starting material was a crude extract enriched in fimbriae and flagella, according to the method of Freurier et al. [20]. LPS and porins were recognized with polyclonal serum from rabbits hyper-immunized with LPS and porins, respectively (sera obtained from the Department of Microbiology, University of Navarra, Spain). OmpA was identified based on its different mobility in SDS-PAGE when the samples are incubated in SDS sample buffer at $100^{\circ} \mathrm{C}$ or at room temperature [9].

\section{RESULTS}

\subsection{Characterization of $\mathrm{HE}$ extract}

The electron microscopy studies suggest that after a heat treatment of whole cells small spherical vesicles ranging from 15 to $40 \mathrm{~nm}$ were released. Other filamentous appendages were seen (Fig. 1). This material was called the HE extract. The protein content of the HE extract obtained from $S$. Enteritidis 3934 was $31.35 \pm 4.55 \%$, and the LPS percentage was $69.14 \pm 1.90 \%(n=$ $10)$.

The SDS-PAGE profile of HE was similar to OMPs enriched fraction, containing 


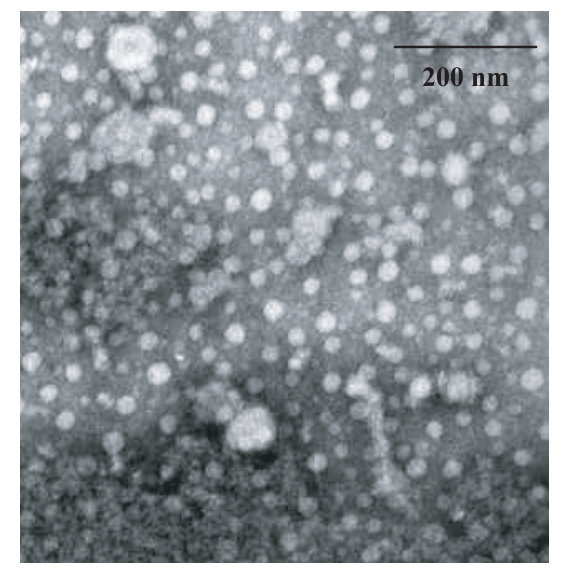

Figure 1. Electron microscopy of the antigenic extract (HE) from Salmonella Enteritidis. Negative staining $(\times 60000)$.

porins (35-36 kDa) and OmpA (34 kDa). There are other major proteins in the HE extract that appear by SDS-PAGE with apparent molecular weights of 22.1, 23.1, $25.2,26.8,28.4,30.3$ and $45.1 \mathrm{kDa}$ (Figs. 2A and 2B). Their presence in the outer membrane extract (sequential detergent extraction from cell envelopes, see Materials and Methods, Sect. 2.3) strongly suggests their OMP nature. In addition, HE comprised surface appendages such as flagellin (53 kDa), SEF14 (14 kDa) and SEF21 (21 kDa) (Fig. 2A).

\subsection{Immunoblot analyses of the HE}

Figure 3 shows some representative results of the immunoblotting performed. The higher frequency of reactants of naturally infected hens sera was observed against porins (97.3\%), OMP of $22.1 \mathrm{kDa}$ (66.2\%), and OmpA (64.7\%), although a reactivity against SEF14, SEF21, LPS and flagellin was also seen $(50.0 \%, 60.8 \%$, $81.8 \%$ and $47.3 \%$ ) (Tab. I). A reaction against the other OMPs defined by its

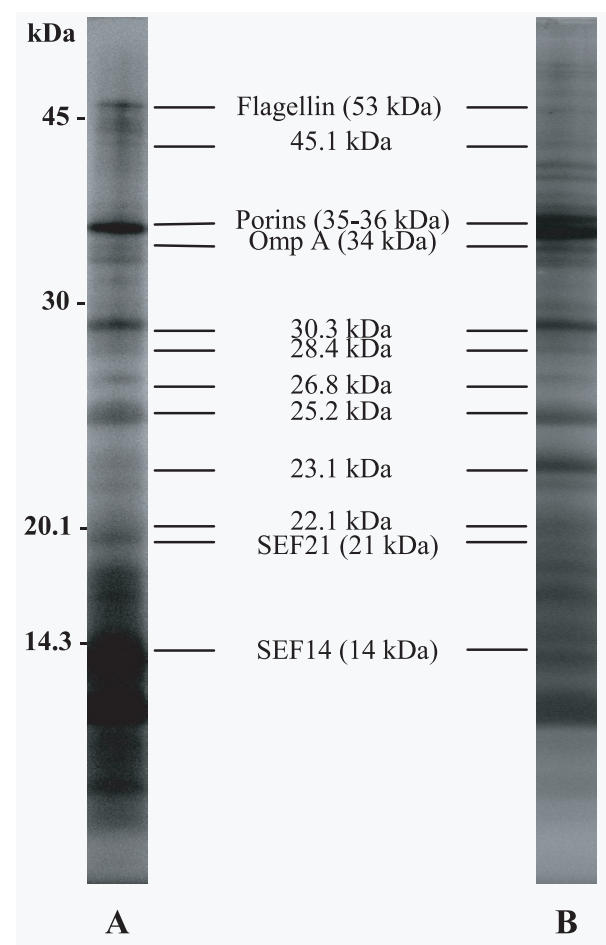

Figure 2. SDS-PAGE of HE (A) and OMP (B) of Salmonella Enteritidis. Silver staining for proteins. The position of some identified bands is indicated by arrows.

molecular weight was observed between $50.0 \%$ and $63.5 \%$. There was a frequent but weak reactivity to LPS and porins when HE was tested against the sera from healthy hens $(86.7 \%$ and $66.7 \%$, respectively), in contrast to the low percentage of seropositivity against the rest of the components (SEF14, 6.6\%; SEF21, 3.3\%; OmpA, 6.7\%; Flagella, $0.0 \%$ ). These results suggest that there is a specific reactivity of sera from naturally infected hens with $S$. Enteritidis against SEFs, OmpA and flagella. By contrast, the reaction against LPS and porins could not be distinguished between non infected and naturally infected hens. 


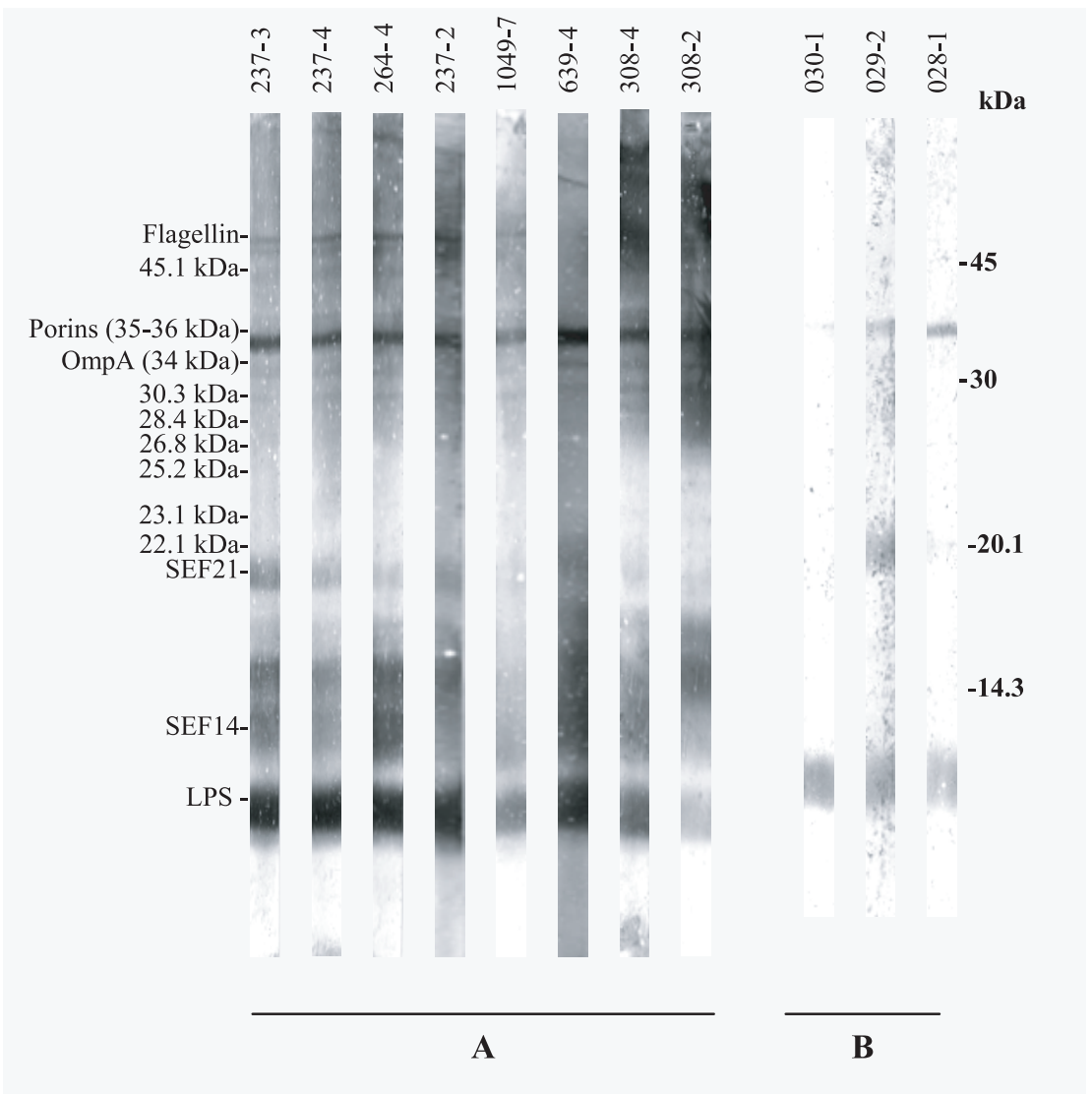

Figure 3. Immunoblot analyses of sera from hens bacteriologically positive (A) and negative (B) for Salmonella Enteritidis against the HE components. Lane numbers correspond to animal reference numbers.

\section{DISCUSSION}

In order to determine the most immunogenic components of the surface of $S$. Enteritidis, we studied by immunoblotting the reaction of sera from naturally infected reproductive hens to an extract that contains surface proteins and external appendages of the bacteria. The immunogenicity of these components during natural infection would indicate their possible role as inductive antigens in a subcellular vaccine for its use in poultry.

Salmonella possess surface structures that can induce protective humoral and cellular immune responses following experimental infection in poultry $[16,30]$. These components include LPS, OMPs, fimbriae and flagellin. We obtained an antigenic extract of $S$. Enteritidis (called HE) by a simple procedure that, instead of other antigenic extracts found in the literature, contains 
Table I. Frequency of reactants (\%) observed by immunoblotting of each serum sample group against the main antigenic components present in the HE of Salmonella Enteritidis.

\begin{tabular}{lcc}
\hline & $\begin{array}{c}\text { Group 1 } \\
\text { (Infected) } \\
n=74\end{array}$ & $\begin{array}{c}\text { Group 2 } \\
\text { (Healthy) } \\
n=30\end{array}$ \\
\hline LPS & 81.8 & 86.7 \\
SEF 14 & 50.0 & 6.6 \\
SEF 21 & 60.8 & 3.3 \\
$22.1 \mathrm{kDa}$ & 66.2 & 0.0 \\
$23.1 \mathrm{kDa}$ & 50.0 & 0.0 \\
$25.2 \mathrm{kDa}$ & 54.1 & 0.0 \\
$26.8 \mathrm{kDa}$ & 54.0 & 0.0 \\
$28.4 \mathrm{kDa}$ & 47.2 & 0.0 \\
$30.3 \mathrm{kDa}$ & 59.4 & 0.0 \\
OmpA & 64.7 & 6.7 \\
Porins & 97.3 & 66.7 \\
$45.1 \mathrm{kDa}$ & 63.5 & 0.0 \\
Flagella & 47.3 & 0.0 \\
\hline
\end{tabular}

a Group 1, naturally infected with $S$. Enteritidis; group 2, Salmonella culture negative.

outer membrane antigens together with SEFs and flagellin, the main structural surface components of the bacteria.

In this study, performed with sera from naturally infected laying hens, the strongest response (higher number of hen reactants) was observed against porins $(97.3 \%)$ and OmpA $(64.7 \%)$, although antibodies against SEF14, SEF21, LPS and flagellin were also seen $(50.0 \%, 60.8 \%, 81.8 \%$ and $47.3 \%)$. The reactivity against SEF14, SEF21 and other unidentified OMPs, with apparent molecular masses of $30.5,35.8,41$, and 55, may correspond with some of the major antigenic proteins from whole cells of $S$. Enteritidis described by Barbour et al. [1] that reacted with sera from experimentally infected chickens. These authors studied the chronological recognition of polypeptides from the whole cells of $S$. Enteritidis, but we can not discuss this aspect since we tested serum samples from naturally infected hens.

Our results indicate a frequent although weak reaction against LPS (86.7\%) and porins $(66.7 \%)$ with the sera of healthy hens, probably as a result of the immune cross-reaction between $S$. Enteritidis with other enterobacteria commonly in contact with the animals. Thus, the cross-reactivity among the Enterobacteriaceae family is, at least in part, caused by an immune response directed against the immunodominant "O" antigen of LPS [3, 4, 13]. Porins are also conserved in many Gram-negative species, including Enterobacteriaceae, therefore, it was not unexpected to find antibodies in healthy hens against these proteins [26, 27]. These cross-reactions were not observed in the case of flagellin and fimbriae, indicating the specificity of the antibodies generated against these surface components during an infection by $S$. Enteritidis in hens. In fact, different authors have taken advantage of this property employing these components individually for the development of specific serodiagnostic tests, like SEF14 and flagellin in ELISA [2, 5, 11, 24, 29, 33].

Our results provide evidence that the components of the HE extract, highly immunogenic in the course of a natural infection in hens, might serve as effective components of a subcellular vaccine. The protective efficacy of these extracts is currently under investigation.

\section{ACKNOWLEDGMENTS}

This work was supported by a grant from the "Departamento de Educación del Gobierno de Navarra", Spain (Grant 96/2000). Javier Ochoa is being supported by a grant from the "Instituto Nacional de Investigación y Tecnología Agraria y Alimentaria (INIA-Spain)". The authors wish to thank M ${ }^{\mathrm{a}}$ José Solsona (CESAC, Reus, Spain) and Veterinary Laboratories Agency (Surrey, UK) for kindly supplying the naturally infected hens sera and monoclonal antibodies against SEF14 and SEF21 respectively, employed in this study. 


\section{REFERENCES}

[1] Barbour E.K., El Jurdi L.H., Faroo O.M., Daghir N.J., Bouljihad M., Chronological recognition by chicken of antigenic polypeptides in Salmonella enteritidis with different plasmid profiles: relationship to infection rate, J. Vet. Med. Sci. 62 (2000) 565-570.

[2] Barrow P.A., Serological diagnosis of Salmonella serotype enteritidis infections in poultry by ELISA and other tests, Int. J. Food Microbiol. 21 (1994) 55-68.

[3] Barrow P.A., Berchieri A. Jr., al-Haddad O., Serological response of chickens to infection with Salmonella gallinarum-S. pullorum detected by enzyme-linked immunosorbent assay, Avian Dis. 36 (1992) 227-236.

[4] Blanden R.V., Mackaness G.B., Collins F.M., Mechanisms of acquired resistance in mouse typhoid, J. Exp. Med. 124 (1966) 585-600.

[5] Cooper G.L., Thorns C.J., Evaluation of SEF14 fimbrial dot blot and flagellar western blot tests as indicators of Salmonella enteritidis infection in chickens, Vet. Rec. 138 (1996) 149-153.

[6] Darwin A.J., Miller V.L., Identification of Yersinia enterocolitica genes affecting survival in an animal host using signature-tagged transposon mutagenesis, Mol. Microbiol. 32 (1999) 51-62.

[7] Fantasia M., Filetici E., Anastasio M.P., Marcozzi M.D., Gramenzi M.P., Aureli P., Italian experience in Salmonella enteritidis 1978-1988: characterization of isolates from food and man, Int. J. Food Microbiol. 12 (1991) 353-362.

[8] Filip C., Fletcher G., Wulff J.L., Earhart C.F., Solubilization of the cytoplasmic membrane of Escherichia coli by the ionic detergent sodium-lauryl sarcosinate, J. Bacteriol. 115 (1973) 717-722.

[9] Gamazo C., Vitas A.I., Moriyon I., LopezGoni I., Diaz R., Brucella group 3 outer membrane proteins contain a heat-modifiable protein, FEMS Microbiol. Lett. 112 (1993) 141146.

[10] Gamazo C., Winter A.J., Moriyon I., RiezuBoj J.I., Blasco J.M., Diaz R., Comparative analyses of proteins extracted by hot saline or released spontaneously into outer membrane blebs from field strains of Brucella ovis and Brucella melitensis, Infect. Immun. 57 (1989) 1419-1426.

[11] Gast R.K., Porter R.E. Jr., Holt P.S., Assessing the sensitivity of egg yolk antibody testing for detecting Salmonella enteritidis infections in laying hens, Poult. Sci. 76 (1997) 798-801.

[12] Gast R.K., Nasir M.S., Jolley M.E., Holt P.S., Stone H.D., Serologic detection of experimental Salmonella enteritidis infections in laying hens by fluorescence polarization and enzyme immunoassay, Avian Dis. 46 (2002) 137-142.

[13] Hormaeche C.E., Mastroeni P., Harrison J.A., Demarco de Hormaeche R., Svenson S., Stocker B.A., Protection against oral challenge three months after i.v. immunization of $\mathrm{BALB} / \mathrm{c}$ mice with live Aro Salmonella typhimurium and Salmonella enteritidis vaccines is serotype (species)-dependent and only partially determined by the main LPS $\mathrm{O}$ antigen, Vaccine 14 (1996) 251-259.

[14] Humphrey T.J., Contamination of eggs and poultry meat with Salmonella enterica serovar Enteritidis, in: Saed A.M., Gast R.K., Potter M.E., Wall P.G. (Eds.), Salmonella enterica serovar Enteritidis in Humans and Animals; Pathogenesis and Control, Iowa State University Press, Ames, 1999, pp. 183192.

[15] Laemmli U.K., Cleavage of structural proteins during the assembly of the head of bacteriophage T4, Nature 227 (1970) 680-685.

[16] Liu W., Yang Y., Chung N., Kwang J., Induction of humoral immune response and protective immunity in chickens against Salmonella enteritidis after a single dose of killed bacterium-loaded microspheres, Avian Dis. 45 (2001) 797-806.

[17] Lowry O.H., Rosebrough N.J., Farr A.L., Randall R.J., Protein measurement by the Folin phenol reagent, J. Biol. Chem. 193 (1951) 265-275.

[18] Lu S., Manges A.R., Xu Y., Fang F.C., Riley L.W., Analysis of virulence of clinical isolates of Salmonella enteritidis in vivo and in vitro, Infect. Immun. 67 (1999) 5651-5657.

[19] Meyer H., Animals as sources of infections in humans-salmonellosis, Dtsch. Tierarztl. Wochenschr. 106 (1999) 344-351.

[20] Ogunniyi A.D., Manning P.A., Kotlarski I., A Salmonella enteritidis 11RX pilin induces strong T-lymphocyte responses, Infect. Immun. 62 (1994) 5376-5383.

[21] Osborn M.J., Studies on the gram negative cell wall. I. Evidence for the role of the 2-Keto, 3-deoxyoctonate in the lipopolysaccharide of Salmonella typhimurium, Proc. Natl. Acad. Sci. USA 50 (1963) 499-506.

[22] Palmer S., Parry S., Perry D., Smith R., Evans M., Nehaul L., Roberts R., Walapu M., Wright 
D., The role of outbreaks in developing food safety policy: population based surveillance of Salmonella outbreaks in Wales 1986-98, Epidemiol. Infect. 125 (2000) 467-472.

[23] Proux K., Jouy E., Houdayer C., Protais J., Dibb-Fuller M., Boscher E., Gillard A., Gracieux P., Gilbert F., Beaumont C., DuchetSuchaux M., Reliable ELISAs showing differences between resistant and susceptible lines in hens orally inoculated with Salmonella Enteritidis, Vet. Res. 33 (2002) 23-33.

[24] Rajashekara G., Munir S., Lamichhane C.M., Back A., Kapur V., Halvorson D.A., Nagaraja K.V., Application of recombinant fimbrial protein for the specific detection of Salmonella enteritidis infection in poultry, Diagn. Microbiol. Infect. Dis. 32 (1998) 147-157.

[25] Seo K.H., Holt P.S., Brackett R.E., Gast R.K., Stone H.D., Mucosal humoral immunity to experimental Salmonella enteritidis infection in the chicken crop, Avian Dis. 46 (2002) 1015-1020.

[26] Simonet V., Mallea M., Fourel D., Bolla J.M., Pages J.M., Crucial domains are conserved in Enterobacteriaceae porins, FEMS Microbiol. Lett. 136 (1996) 91-97.

[27] Singh S.P., Upshaw Y., Abdullah T., Singh S.R., Klebba P.E., Structural relatedness of enteric bacterial porins assessed with monoclonal antibodies to Salmonella typhimurium OmpD and OmpC, J. Bacteriol. 174 (1992) 1965-1973.
[28] Thiagarajan D., Thacker H.L., Saeed A.M., Experimental infection of laying hens with Salmonella enteritidis strains that express different types of fimbriae, Poult. Sci. 75 (1996) $1365-1372$

[29] Thorns C.J., Sojka M.G., McLaren I.M., Dibb-Fuller M., Characterisation of monoclonal antibodies against a fimbrial structure of Salmonella enteritidis and certain other serogroup D salmonellae and their application as serotyping reagents, Res. Vet. Sci. 53 (1992) 300-308.

[30] Timms L.M., Marshall R.N., Breslin M.F., Laboratory and field trial assessment of protection given by a Salmonella enteritidis PT4 inactivated, adjuvant vaccine, Br. Vet. J. 150 (1994) 93-102.

[31] Towbin H., Staehelin T., Gordon J., Electrophoretic transfer of proteins from polyacrylamide gels to nitrocellulose sheets: procedure and some applications, Proc. Natl. Acad. Sci. USA 76 (1979) 4350-4354.

[32] Warren L., The thiobarbituric acid assay of sialic acids, J. Biol. Chem. 243 (1959) 19711975.

[33] Zamora B.M., Hartung M., Hildebrandt G., Simplified preparation of a specific $S$. enteritidis antigen for ELISA and other immunological techniques, Zentralbl. Veterinaermed. 46 (1999) 1-7. 